\title{
Potential favourable health effects of some dietary uncommon fatty acids
}

\author{
Charles Coudray ${ }^{1}$, Erwann Durand ${ }^{2,3}$, Laurence Balas ${ }^{4}$, Ariane Sultan ${ }^{5,6}$, François Casas ${ }^{1}$ \\ and Christine Feillet-Coudray ${ }^{1, *}$ \\ ${ }^{1}$ DMEM, Univ Montpellier, INRAE Montpellier, Montpellier, France \\ 2 CIRAD, UMR Qualisud, 34398 Montpellier, France \\ ${ }^{3}$ Qualisud, Univ Montpellier, Avignon Université, CIRAD, Institut Agro, IRD, Université de La Réunion, Montpellier, France \\ ${ }^{4}$ Institut des Biomolécules Max Mousseron, Univ Montpellier, UMR 5247, CNRS, ENSCM, Montpellier, France \\ ${ }^{5}$ Université de Montpellier, PhyMedExp, Inserm, CNRS, 34000 Montpellier, France \\ ${ }^{6}$ Montpellier University Hospital, Department of Endocrinology-Diabetes-Nutrition, 34295 Montpellier Cedex 5, France
}

Received 3 May 2021 - Accepted 13 July 2021

\begin{abstract}
In addition to the major fatty acids widely studied, our diet contains many bioactive fatty acids less frequently investigated such as n-3 docosapentaenoic acid(n-3 DPA), natural trans fatty acids, conjugated fatty acids (CLAs), furan fatty acids (FuFAs), branched chain fatty acids (BCFAs) and fatty acid esters of hydroxyl fatty acids (FAHFAs). Many of them may have beneficial health effects, particularly in the prevention of cardiovascular diseases, inflammation and metabolic disorders such as diabetes. This review aims to give a brief overview of the current knowledge on these lipids. Thus, information about biosynthesis, food and tissue content, daily intake, biological and potential health effects of these fatty acids is provided.
\end{abstract}

Keywords: bioactive lipids / biosynthesis / food content / dietary intake / biological and health effects

Résumé - Effets potentiellement bénéfiques sur la santé de certains acides gras peu courants de l'alimentation. Parallèlement aux acides gras prépondérants qui sont largement étudiés, notre alimentation contient de nombreux acides gras bioactifs moins fréquemment considérés tels que l'acide docosapentaénoïque n-3 (n-3 DPA), des acides gras trans naturels, des acides gras conjugués (CLAs), des acides gras furaniques (FuFAs), des acides gras à chaîne ramifiée (BCFAs) et des esters d'acides gras hydroxylés (FAHFAs). Nombreux d'entre eux peuvent avoir des effets bénéfiques sur la santé, notamment dans la prévention des maladies cardiovasculaires, de l'inflammation et des troubles métaboliques tels que le diabète. Cette revue vise à donner un bref aperçu des connaissances actuelles sur ces lipides. Ainsi, des informations sur la biosynthèse, les teneurs tissulaires et dans les aliments, l'apport alimentaire quotidien, les effets biologiques et les effets santé potentiels de ces acides gras sont rapportés.

Mots clés : lipides bioactifs / biosynthèse / composition des aliments / apport alimentaire / effets biologiques et sur la santé

Food plays an important role not only for an optimal growth and development but also in the maintenance of a good health. While the role of nutrients and micronutrients and the needs of the organism in these components are widely studied, there are many molecules in our diet whose roles are yet to be investigated more extensively. These include many bioactive lipids with potential beneficial health effects such as n-3 docosapentaenoic acid(n-3 DPA), natural trans fatty acids, conjugated fatty acids (CLAs), furan fatty acids (FuFAs), branched chain fatty acids (BCFAs) and fatty acid

\footnotetext{
*Correspondence: christine.coudray@inrae.fr
}

hydroxylated fatty acid esters (FAHFAs). This review aims to give a brief overview of the current knowledge regarding these lipids. We present their structure and their biosynthesis (Fig. 1 for precursors and structure of these lipids), their content in food and their daily intake (Tab. 1), their tissue content, their biological and potential health effects. Some dietary lipids can be toxic (cyclopropene-containing lipids, mono-unsaturated long-chain fatty acids as erucic acid, trans-unsaturated fatty acids from industrial hydrogenated fats, and lipid peroxides) (Gurr et al., 2002). However, except trans fatty acids of industrial origin, they are not discussed in this article. 

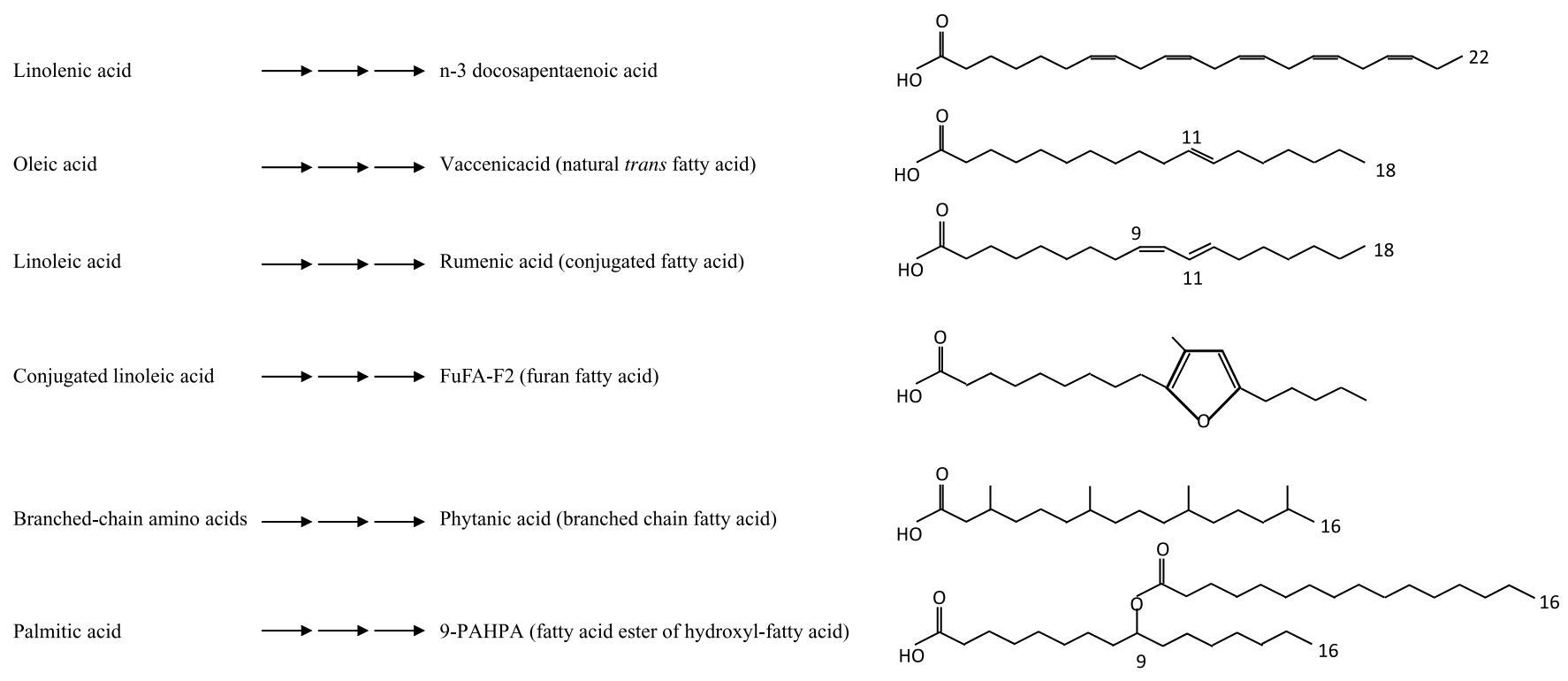

Fig. 1. Examples of some uncommon fatty acids and their precursors.

Table 1. Daily intake and main dietary sources of some bioactive lipids.

\begin{tabular}{|c|c|c|}
\hline n-3 DPA & 10 to $100 \mathrm{mg} / \mathrm{d}$ & Seafood \\
\hline Natural trans fatty acids & 0.5 to $0.9 \%$ total energy intake & $\begin{array}{l}\text { Dairy products } \\
\text { Beef and lamb meat }\end{array}$ \\
\hline CLAs & Hundreds of milligrams/d & $\begin{array}{l}\text { Dairy products } \\
\text { Beef and lamb meat }\end{array}$ \\
\hline FuFAs & Tens of milligrams/d & Fish \\
\hline FAHFAs & No data available & $\begin{array}{l}\text { Animal products } \\
\text { Plant products and milk }\end{array}$ \\
\hline
\end{tabular}

DPA: docosapentaenoic acid; CLAs: conjugated fatty acids; FuFAs: furan fatty acids; BCFAs: branched chain fatty acids; FAHFAs: fatty acid esters of hydroxyl fatty acids.

\section{The n-3 docosapentaenoic acid DPA}

\subsection{Structure and biosynthesis}

n-3 DPA (C22:5 n-3) belongs to the $n-3$ polyunsaturated fatty acid (PUFA) family. It is also called clupanodonic acid. It is an intermediate between eicosapentaenoic acid (EPA, C20:5 $\mathrm{n}-3)$ and docosahexaenoic acid(DHA, C22:6 n-3) in the conversion pathway of n-3 PUFA from $\alpha$-linolenic acid (ALA, C18:3 n-3). n-3 DPA as a reservoir is metabolized into DHA, and further retro-conversed back to EPA (Guo et al., 2020).

\subsection{Food content and daily intake}

n-3 DPA is present in numerous foods in notable quantities, in particular in seafood ( 1 to $5 \%$ of total fatty acids in fish, i.e. up to $1 / 3$ of EPA or DHA levels taken individually) as well as in human breast milk ( $0.2 \%$ of total fatty acids) (Drouin, 2018). For example, fish oils such as menhaden or sardine oil contain in percentage of total fatty acids: $10-13 \%$ EPA, $2-5 \%$ DPA and
9-11\% DHA. Atlantic salmon contains $0.3 \mathrm{~g}$ of EPA, $0.3 \mathrm{~g}$ of DPA and $1.1 \mathrm{~g}$ of DHA per $100 \mathrm{~g}$. (Kaur et al., 2016).

The estimated average consumption of n-3 DPA is between 10 and $106 \mathrm{mg} / \mathrm{d}$ in Western countries and Japan (Richter et al., 2019). n-3 DPA may represent a significant proportion of the total long-chain n-3 fatty acid intake, depending on the population, up to $30 \%$ of average total long-chain $n-3$ fatty acid intake in some cases (Richter et al., 2019). However, the digestibility of n-3 DPA in rodents (digestibility reflecting net absorption in the digestive tract after enzymatic hydrolysis by digestive enzymes and microflora of the gastrointestinal tract) is lower than that of EPA and DHA (Drouin et al., 2019a).

\subsection{Tissue content and biological functions}

The majority of the tissues present n-3 DPA levels in the order of 5\% compared to DHA levels (Ghasemi Fard et al., 2021). In the brain, n-3 DPA is the second n-3 PUFA found, although at levels 70 times lower than DHA (Drouin et al., 2019b). 
n-3 DPA is a source of EPA and to a lesser extent DHA in major metabolic tissues (liver, heart, lung, spleen and kidney), two fatty acids with numerous known health benefits. Moreover, n-3 DPA is the precursor of many major lipid mediators (protectins, resolvins, maresins, isoprostanoids), involved in the pro-resolution of inflammation, with specific effects compared to other n-3 PUFAs (Ghasemi Fard et al., 2021).

\subsection{Health effects}

Low commercial availability of n-3 DPA in sufficient quantity, at high purity and at an affordable price (Drouin, 2018; Drouin et al., 2019b) has limited its studies in rodents and humans. Thus, only 11 studies in animals and 2 studies in humans with n-3 DPA in pure form have been reported (Ghasemi Fard et al., 2021). The effects of n-3 DPA on lipid parameters associated with the prevention of cardiovascular diseases are the most documented (anti-inflammatory properties, inhibition of cytokine synthesis, reduction of thrombosis and inhibition of atherosclerosis, ...) (von Schacky and Harris, 2018). The health effects of n-3 DPA could be both independent and shared with EPA and DHA (Richter et al., 2019). It is important to note that the n-3 DPA could contribute to increasing the n-3 fatty acid status, as n-3 DPA is more present in meat than EPA or DHA and while the sources of fatty fish are limited; therefore, n-3 DPA could be helpful to maintain a suitable $n-6 / n-3$ ratio which is the indicator of a preventive diet for the control of non-communicable diseases (Drouin et al., 2019b). Drouin et al. recently published a comprehensive review on n-3 DPA (Drouin et al., 2019b).

\section{The trans fatty acids}

\subsection{Structure and biosynthesis}

Trans fatty acids are fatty acids that have at least one double bond in the trans configuration while most of the naturally occurring unsaturated fatty acids contain cis-double bonds. Naturally occurring trans fatty acids are mostly monounsaturated fatty acids, mainly trans $\mathrm{C} 18: 1 \mathrm{n}-7$ (vaccenic acid), trans-C16:1 n-7 and all isomers of oleic acid (18:1 n-9) (Leray, 2013). There are also di-unsaturated trans fatty acids, derived from linoleic acid (18:2 n-6) or tri-unsaturated trans fatty acids, derived from linolenic acid (18:3n-3). Conjugated linoleic acids (two conjugated double bonds, one of which is in a trans configuration) are discussed in Section 3.

Naturally occurring trans fatty acids come from a bacterial isomerisation of fatty acids in the digestive tract of ruminants (Leray, 2013). The eukaryotes are unable to synthesize them, however, it is possible that they can be synthesised by the action of intestinal microbiota on dietary fatty acids. Trans fatty acids of industrial origin are formed during the partial hydrogenation of vegetable or fish oils. Thermal treatments (frying, cooking, ...) can also produce trans fatty acids of (poly)unsaturated oils and fats.

\subsection{Food content and daily intake}

Trans fatty acids of natural origin are found in dairy products and beef and sheep meats. Butter contains 3 to $7 \mathrm{~g} / 100 \mathrm{~g}$ of natural trans fatty acids, cheeses from 1.3 to $2 \mathrm{~g} / 100 \mathrm{~g}$, whole milks around $0.15 \mathrm{~g} / 100 \mathrm{~g}$, vegetable oils between 0.5 and $2 \mathrm{~g} / 100 \mathrm{~g}$, beef and sheep meat from 0.1 to $0.5 \mathrm{~g} / 100 \mathrm{~g}$ (Leray, 2013). Trans fatty acids from industrial process are used by the food industry as stabilizers and preservatives. Thus, they are found in many processed food products such as pastries, pizzas, quiches (Afssa, 2005).

According to the results of the INCA2 survey, the average and $95^{\text {th }}$ percentile intake of the total trans fatty acids in the French population was estimated at $1-1.5 \%$ of total energy intake, regardless of age and sex (Afssa, 2009). More than half is of natural origin $(0.5-0.9 \%)$, thus below the ANSES recommendations to limit the total trans fatty acid intake to less than $2 \%$ of the total energy intake (Afssa, 2009).

\subsection{Tissue content and biological functions}

In the $2000 \mathrm{~s}$, the total amount of trans fatty acids was $2.32 \pm 0.50 \%$ of the total fatty acids in adipose tissue of French women (Boue et al., 2000) and mean adipose tissue levels were lower in many European countries than in the USA (Arab, 2003)

The trans configuration impacts the physicochemical and functional properties of monounsaturated fatty acids. It makes them closer to the properties of the corresponding saturated fatty acids. Thus, high amounts of trans fatty acids may decrease the membrane fluidity and increase the oxidative stress (Leray, 2013), and may induce inflammation and apoptosis of the cells (Qiu et al., 2018).

\subsection{Health effects}

A number of epidemiological studies have shown a relationship between trans fatty acid intake and cardiovascular diseases. Controlled feeding studies suggest that dietary trans fatty acids raise serum cholesterol concentrations to a very similar extent as saturated fatty acids (Gurr et al., 2002; Leray, 2013). Numerous studies show that the risks of cardiovascular diseases with dietary trans fatty acids are attributable to industrial trans fatty acid (Oteng and Kersten, 2020). In contrast, no increase in cardiovascular risk has been observed with the consumption of naturally occurring trans fatty acids at the current consumption levels (Guillocheau et al., 2019). Studies on cells, rodents and humans suggest physiological benefits on inflammation, type 2 diabetes and obesity (Guillocheau et al., 2019), without knowing whether these naturally occurring trans fatty acids act directly or through their metabolites (Guillocheau et al., 2019). Guillocheau et al. recently published a comprehensive review on natural trans fatty acids (Guillocheau et al., 2019).

\section{The conjugated linoleic acid CLAs}

\subsection{Structure and biosynthesis}

Conjugated linoleic acid(CLA) is a collective term for a mixture of positional and geometrical isomers of linoleic acid(LA,C18:2 n-6) containing conjugated double bounds. Some linoleic acid isomers have conjugated doubles with one of them (at least) in a trans configuration (Leray, 2013). 
Rumenic acid(9-cis, 11-trans 18:2 n-6) is the most abundant CLA. There are other conjugated fatty acids such as conjugated linolenic acids (CLNAs), conjugated eicosapentaenoic acids (CEPAs) and conjugated docosahexaenoic acid (CDHAs) (Leray, 2013).

CLAs are produced naturally in the rumen of ruminant animals by fermentative bacteria (Butyrivibrio fibrisolvens) which isomerize linoleic acid into CLAs. Ruminants also synthesize CLAs by delta9-desaturase and from trans-11 18:1 (Leray, 2013).

\subsection{Food content and daily intake}

Of the possible isomers of CLA, about 20 have been identified in foods (Leray, 2013). Beef meat contains up to $120 \mathrm{mg} / 100 \mathrm{~g}$ of CLA and lamb meat about $80 \mathrm{mg} / 100 \mathrm{~g}$. The main isomer present in milk fat is the rumenic acid, which accounts for $80 \%$ to $90 \%$ of the total CLA. Rumenic acid represents up to $700 \mathrm{mg} / 100 \mathrm{~g}$ in butter and up to 100 to $250 \mathrm{mg} / 100 \mathrm{~g}$ in cheese. Women's milk contains the same amount as cow's milk (10 mg/100 g). CLA, including rumenic acid, can also be found after heating vegetable oils and in certain food products. In fact, it is possible to obtain CLA through the partial hydrogenation of linoleic acid or by thermal treatments, and thus to find up to $0.5 \mathrm{~g}$ of CLA for $100 \mathrm{~g}$ of products in certain food products (industrial pasta, cookies) (Leray, 2013).

The intake of CLA from a typical diet is estimated at several $100 \mathrm{mg} / \mathrm{d}$ in various countries (Parodi, 2003). In the $2000 \mathrm{~s}$, mean daily intake of rumenic acid was $250 \mathrm{mg} / \mathrm{d}$ to $320 \mathrm{mg} / \mathrm{d}$ in female students in Germany (Fremann et al., 2002), mean daily intake of CLA was $176 \mathrm{mg}$ total CLA/d for men and $104 \mathrm{mg}$ for women in the USA and was estimated to be almost $100 \mathrm{mg}$ in the UK (Ritzenthaler et al., 2001).

\subsection{Tissue content and biological functions}

To our knowledge, no data are found in the literature on CLA tissue content in human. It was demonstrated in vitro and in vivo in animal models that CLA plays a major role in lipid metabolism, especially as regards the oxidative cellular system. In fact, in conjugated fatty acids, the electrons become delocalized over conjugated double bonds, conferring to CLA unusual chemical properties (Gurr et al., 2002). In addition to its role on lipid metabolism and lipid peroxidation, the impact of CLA on energy expenditure, insulin metabolism and inflammation were also observed (Lehnen et al., 2015; Wang et al., 2020a).

\subsection{Health effects}

Some animal studies show that CLA (and also CLNA, CEPA, CDHA) may have some beneficial health effects such as reduction of body fat, improved insulin resistance, antithrombogenic and anti-carcinogenic effects, reduction of atherosclerosis, improved lipid profile, modulation of the immune system and stimulation of bone mineralization (Wang et al., 2020a). The most studied CLA supplementation effect is its capacity to alter the body composition, promoting an increase in lean mass and reduction of the fatty mass
(Lehnen et al., 2015). However, in humans, the clinical evidence appears to be insufficient and not unanimous regarding the health effects of CLA (Ritzenthaler et al., 2001; Lehnen et al., 2015). Of the different isomers of CLA, rumenic acid has been reported to be the most bioactive CLA (Belury, 1995). Lehnen et al. recently published a comprehensive review on CLAs (Lehnen et al., 2015).

\section{The furan fatty acids FuFAs}

\subsection{Structure and biosynthesis}

The furan fatty acids (FuFAs) are fatty acids with a furan ring. To date, thirty different structures have been identified (Glass et al., 1974; Wang et al., 2020b). The most common FuFAs are methylated or dimethylated forms. However, non-methylated furans have been also described (Yurawecz et al., 1995).

Methylated FuFAs are formed from polyunsaturated fatty acids, in particular linoleic acid (Batna et al., 1993) and nonmethylated FuFAs are formed from conjugated dienes, in particular CLA (Yurawecz et al., 1995). Currently, the biosynthetic pathway of FuFAs is not completely established and might depend on the species considered (plant, bacteria, animal, ...).

\subsection{Food content and daily intake}

Fish are an important source of FuFAs, with 1 to $4 \%$ of total fatty acids in the form of FuFAs (Vetter et al., 2012). Butter and dairy products contain 5 to $50 \mathrm{mg} / 100 \mathrm{~g}$ FuFAs (Vetter et al., 2012; Wendlinger and Vetter, 2014). FuFAs have been found in wheat, rice, potatoes, cabbage, orange, lemon, raspberries, with levels ranging from 1 to $350 \mu \mathrm{g} / \mathrm{g}$ dry matter (Hannemann etal., 1989). Soybeans contain FuFAs at levels of 30 to $300 \mu \mathrm{g} / \mathrm{g}$ (Guth and Grosch, 1991; Wu et al., 1997) while the levels are not quantifiable in olives, sesame, nuts, grape seeds and sunflower (Wahl et al., 1994).

Few data exist on the ingested amount of FuFAs. The estimated average consumption of FuFAs was estimated in Germany in 2014, and observed to be about 10 to $25 \mathrm{mg}$ /day (6.6 to $16.5 \mathrm{mg}$ via fish, $0.7-4.8 \mathrm{mg}$ via milk fat, 1.4 to $2.5 \mathrm{mg}$ via soybean oil, $0.2-0.5 \mathrm{mg}$ via rapeseed oil and $0.008 \mathrm{mg}$ via olive oil) (Wendlinger and Vetter, 2014).

\subsection{Tissue content and biological functions}

To our knowledge, no data are found in the literature on FuFAs tissue content in human. FuFAs possess antioxidant properties due to the presence of the furan ring (Okada et al., 1990, 1996; Masuchi Buscato et al., 2020). They also have anti-microbial (Knechtle et al., 2014; Dasagrandhi et al., 2016; Kimura et al., 2018) and anti-inflammatory (Wakimoto et al., 2011; Khan et al., 2018; Lauvai et al., 2019) properties. FuFAs may thus participate to the anti-inflammatory effects of fish oils and fish-based diets.

\subsection{Health effects}

FuFAs present in fish may be involved in the beneficial effects of fish consumption on cardiovascular disease (Spiteller, 2005). Several in vitro studies support this hypothesis 
(Graff et al., 1984; Okada et al., 1996; Fuchs and Spiteller, 1999) as well as studies conducted in humans (Wahl et al., 1994; Zheng et al., 2016; Tovar et al., 2017). Moreover, in vitro FuFAs modulate lipid metabolism in adipose tissues (Lengler et al., 2012; Lauvai et al., 2019). The 3-carboxy-4methyl-5-propyl-2-furanpropanoic acid(CMPF), a degradation product of FuFAs, also derived from the metabolism of n3 PUFAs, could prevent or even reverse hepatic steatosis (Prentice et al., 2018; Dai et al., 2019; Mohan et al., 2019). Alvarado et al. recently published a comprehensive review on FuFAs (Alvarado et al., 2021).

\section{The branched chain fatty acids BCFAs}

\subsection{Structure and biosynthesis}

BCFAs are saturated fatty acids with one or more methyl groups in the linear carbon chain. There are two distinct series of BCFAs: the iso-series where the terminal group is $\mathrm{CH} 3$ $\frac{I}{\mathrm{CH}}$ and the anteiso-series where the terminal group is

${ }_{1}^{\mathrm{CH} 3}$ (Gurr et al., 2002). However, branch points can also be found in other positions. More than 50 BCFAs have been identified in ruminant-derived fats (Taormina et al., 2020). Monomethyl BCFAs are the most abundant. Among multimethyl BCFAs, phytanic acid (3,7,11,15-tetramethylhexadecanoic acid) and pristanic acid (2,6,10,14-tetramethylpenta-decanoic acid) are predominant although in lesser amounts compared to monomethyl structures (Leray, 2013; Taormina et al., 2020).

In ruminants, BCFAs are synthesized by microorganisms in the rumen, from dietary branched-chain amino acids such as valine, leucine and isoleucine (Taormina et al., 2020). Wallace et al. (Wallace et al., 2018) demonstrated also that BCFAs were synthesized de novo in adipose tissues from branched-chain amino acids catabolized in mitochondria, and then exported by carnitine acetyltransferase to the cytosol, where they were elongated by fatty acid synthase.

\subsection{Food content and daily intake}

BCFAs occur widely but mainly at low concentrations in animal fat and some marine oils (Gurr et al., 2002). BCFAs are present in the milk and tissues of ruminants consumed by humans (beef, sheep, goat). In cow's milk, the concentration of phytanic acid ranges from 0.16 to $0.59 \mathrm{~g} / 100 \mathrm{~g}$ of lipids and that of pristanic acid from 0.03 to $0.09 \mathrm{~g} / 100 \mathrm{~g}$ of lipids (Leray, 2013). In some wild fishes, BCFAs were only $1 \% \pm 0.5 \%$ (mean $\pm \mathrm{SD}$ ) of the total fatty acids, contributing only a small amount of BCFAs per serving to the diet. Consuming a standardized portion $(70 \mathrm{~g})$ of wild freshwater fish contributes to only small amounts of BCFAs (for instance 2.5-24.2 mg, in the American diet) (Wang et al., 2016). Asian food, fermented soy known as nātto and fermented shrimp paste have high BCFA levels, $1.71 \pm 0.17 \%$ and $3.18 \pm 0.14 \%$ BCFAs, respectively (Wang, 2017), relative to total fatty acids.

Few data exist on the ingested amount of BCFAs. In the USA in 2011, the consumption of milk, cheese and beef contributed to a daily dietary intake of about $400 \mathrm{mg}$ of branched fatty acids (Ran-Ressler et al., 2011). Consumption of chocolate contributed to about $6 \mathrm{mg}$ BCFA/day (Ran-Ressler et al., 2014).

\subsection{Tissue content and biological functions}

In mammalian tissues, BCFAs rarely constitute more than $1-2 \%$ of the total fatty acid pool (Pakiet et al., 2020). BCFA are present in the gut from a very early age and throughout the human life cycle. BCFA are major components of the lipids of Grampositive bacteria (such as Bacillus and Lactobacillus). They play an important regulatory role in fluidity and permeability of bacterial membrane (Taormina et al., 2020). They have a positive influence on the development of commensal bacteria from birth, and on intestinal metabolism (Leray, 2013).

\subsection{Health effects}

BCFAs may contribute to the positive health effects attributed to dairy product consumption. Several in vivo studies show protective effects against inflammation, cancers and metabolic disorders (Ran-Ressler et al., 2014; Taormina et al., 2020). In an animal model, BCFAs play a beneficial role against inflammation in the premature intestine, modulate the microbiota and increase the expression of anti-inflammatory cytokines (Taormina et al., 2020). To date, no data concerning the metabolic effects were reported in humans. However it was suggested that BCFAs may favourably influence insulin sensitivity, energy and glucose metabolism in human (Taormina et al., 2020). Taormina et al. recently published a comprehensive review on BCFA (Taormina et al., 2020).

\section{The branched fatty acid esters of hydroxy fatty acids FAHFAs}

\subsection{Structure and biosynthesis}

FAHFAs are fatty acid esters of hydroxy fatty acids. As multiple combinations of fatty acids (FA) and hydroxylated fatty acids (HFA) are possible, there are hundreds of FAHFAs (Yore et al., 2014; Kuda et al., 2016). Almost 50 families of FAHFAs have been identified, the esters of palmitic acid and hydroxy stearic acid (PAHSA) being the most studied. In each family of branched FAHFAs, several positional isomers are possible, with more than 300 regioisomers identified, and for each isomer, there are also 2 possible configurations (Kuda et al., 2018).

Branched FAHFAs are synthesized in vivo (Yore et al., 2014) or can be obtained exogenously from food. To date, only PAHSA biosynthesis pathway in adipocytes was elucidated, involving esterification of hydroxy fatty acids with acyl-CoA fatty acids by an acyltransferase (Kuda et al., 2018), and storage in adipocyte as FAHFA-containing triacylglycerols (Tan et al., 2019).

\subsection{Food content and daily intake}

Numerous branched FAHFA families have been detected in food of plant origin (fruits, vegetables and cereals) (Zhu et al., 2018; Liberati-Cizmek et al., 2019) and of animal origin (egg, chicken, beef, caribou, moose) (Yore et al., 2014; Pham et al., 2019). Abundance of each FAHFAs varies according to the type of food considered. Total FAHFAs range from 45 to $320 \mathrm{ng} / \mathrm{g}$ in fresh food. Branched FAHFAs were also detected in caribou meat and moose at very high doses $(50 \mu \mathrm{g} / \mathrm{g})$ 
compared to other food sources. Branched FAHFAs are present in breast milk, although at very low concentrations (Kuda et al., 2018).

To our knowledge, no data are available on the amount of FAHFAs ingested daily. Moreover, absorption and bioavailability of dietary FAHAs are unknown.

\subsection{Tissue content and biological functions}

FAHFAs are present in blood and in many tissues in rodent and humans. PAHSA content is around $100 \mathrm{ng} / \mathrm{g}$ in white adipose tissue, $150 \mathrm{ng} / \mathrm{g}$ in brown adipose tissue, and 10-20 ng in liver, kidney and pancreas (Yore et al., 2014). In lung, kidney, thymus, liver and heart FAHFAs content is rather in $\mathrm{pg} / \mathrm{g}$ (Zhu et al., 2017). Short-chain FAHFAs are in a concentration range from 0.84 to $57 \mathrm{pmoles} / \mathrm{mg}$ in the large intestine (Gowda et al., 2020b, 2020c).

Only a few FAHFAs have been studied. They modulate favourably insulin sensitivity and glucose metabolism. In particular, 5- and 9-PAHSA have been reported to improve glucose metabolism and insulin signalling (Yore et al., 2014; Moraes-Vieira et al., 2016; Smith and Kahn, 2016; Syed et al., 2018). 9-PAHPA or 9-OAHPA increased insulin sensitivity, but without modifying glucose tolerance, and increased basal metabolism, both in healthy mice and in obese mice with lower insulin sensitivity (Benlebna et al., 2020a, 2020b). Moreover, 9-PAHPA or 9-OAHPA induced a switch toward a more oxidative contractile phenotype of skeletal muscle, suggesting a muscular origin of the increase in insulin sensitivity observed (Benlebna et al., 2020c). Surprisingly, 9-PAHPA or 9-OAHPA induced hepatic steatosis and fibrosis in some healthy mice but not in obese mice, likely because both FAHFAs had insulinsensitized the healthy liver so much that de novo lipogenesis promoted steatosis/fibrosis (Benlebna et al., 2020a, 2020b). FAHFAs activate GPR120 and GPR40 and increase GLP-1 secretion (Yore et al., 2014; Hammarstedt et al., 2018; Kimura et al., 2020). The FAHFAs studied to date have antiinflammatory effects, as demonstrated both in vitro and in vivo in chronic and acute inflammation models (Yore et al., 2014; Kuda et al., 2016; Lee et al., 2016; Kolar et al., 2019). At least some FAHFAs, notably from omega-3 fatty acid derivedFAHFAs family, may have antioxidant effects (Gowda et al., 2020a).

\subsection{Health effects}

Metabolic dysfunction in adipose tissue of healthy moderately overweight humans is associated with reduced levels of PAHSAs in the same tissue (Hammarstedt et al., 2012; Hammarstedt et al., 2018). In addition, serum PAHSAs levels are reduced in obese patients and in diabetics (Yore et al., 2014; Moraes-Vieira et al., 2016). Thus, beneficial effects of PAHSAs were suggested in human in various metabolic disorders such as type 1 and type 2 diabetes, and in chronic inflammation (Brejchova et al., 2020). Other beneficial health effects have been also suggested, in particular against some cancers (Rodriguez et al., 2019). It is important to note that these health effects of FAHFAs have been demonstrated with pharmacological doses in animal models or linked to circulating FAHFAs levels, but not associated to diet normal content. Several comprehensive reviews on branched FAHFAs have been recently published (Brejchova et al., 2020; Benlebna et al., 2021).

\section{Conclusion}

Human diet contains many uncommon fatty acids with bioactive properties such as n-3 DPA, natural trans fatty acids, CLAs, FuFAs, BCFAs and FAHFAs. Many of them may have favourable effects on health, in particular on prevention of cardiovascular diseases, inflammation and metabolic disorders such as diabetes. It is interesting to note that many of these lipids are found mainly in seafood and in dairy products. As bacteria are involved in the synthesis of some of these fatty acids, the role of intestinal microbiota in their metabolism in humans deserves to be explored. As not only food intake but also bioavailability is important to provide adequate nutrients status, and as bioavailability is still unknown for some of these uncommon fatty acids, this parameter needs to be investigated to better understand their health effects.

Acknowledgement. The authors acknowledge the financial support of the French Lipid Nutrition Group for the work conducted on 9-PAHPA and 9-OAHPA (Benlebna et al., 2020a, $2020 \mathrm{~b}, 2020 \mathrm{c}$ ). We thank all colleagues who have contributed and/or who are co-authors of our publications cited in this review.

Conflicts of interest. The authors declare that they have no conflicts of interest in relation to this article.

\section{References}

Afssa. 2005. Risques et bénéfices pour la santé des acides gras trans apportés par les aliments. Afssa, p. 221.

Afssa. 2009. Avis de l'Agence française de sécurité sanitaire des aliments sur l'estimation des apports en acides gras trans de la population française S.n. 2007-SA-0220, ed. Afssa.

Alvarado K, Durand E, Vaysse L, et al. 2021. Effets bénéfiques potentiels des acides gras furaniques, des lipides alimentaires bioactifs-Potential beneficial effects of furan fatty acids, bioactive food lipids. Cah Nutr Diet 56: 117-125.

Arab L. 2003. Biomarkers of fat and fatty acid intake. J Nutr 133 (Suppl. 3): 925S-932S.

Batna A, Scheinkonig J, Spiteller G. 1993. The occurrence of furan fatty acids in Isochrysis sp. and Phaeodactylum tricornutum. Biochim Biophys Acta 1166: 171-176.

Belury M.A. 1995. Conjugated dienoic linoleate: a polyunsaturated fatty acid with unique chemoprotective properties. Nutr Rev 53: 83-89.

Benlebna M, Balas L, Bonafos B, et al. 2020a. Long-term intake of 9-PAHPA or 9-OAHPA modulates favorably the basal metabolism and exerts an insulin sensitizing effect in obesogenic diet-fed mice. Eur J Nutr.

Benlebna M, Balas L, Bonafos B, et al. 2020b. Long-term high intake of 9-PAHPA or 9-OAHPA increases basal metabolism and insulin sensitivity but disrupts liver homeostasis in healthy mice. J Nutr Biochem 79: 108361.

Benlebna M, Balas L, Pessemesse L, et al. 2020c. FAHFAs Regulate the Proliferation of C2C12 Myoblasts and Induce a Shift toward a More Oxidative Phenotype in Mouse Skeletal Muscle. Int J Mol Sci 21. 
Benlebna M, Balas L, Gaillet S, et al. 2021. Potential physiopathological effects of branched fatty acid esters of hydroxy fatty acids. Biochimie 182: 13-22.

Boue C, Combe N, Billeaud C, et al. 2000. Trans fatty acids in adipose tissue of French women in relation to their dietary sources. Lipids 35: $561-566$.

Brejchova K, Balas L, Paluchova V, Brezinova M, Durand T, Kuda O. 2020. Understanding FAHFAs: From structure to metabolic regulation. Prog Lipid Res 79: 101053.

Dai J, Yi J, Zhang S, et al. 2019. Serum 3-carboxy-4-methyl-5-propyl2-furanpropanoic acid is associated with lipid profiles and might protect against non-alcoholic fatty liver disease in Chinese individuals. J Diabetes Investig 10: 793-800.

Dasagrandhi C. Ellamar JB, Kim YS, Kim HR. 2016. Antimicrobial activity of a novel furan fatty acid, 7, 10-epoxyoctadeca-7, 9-dienoic acid against methicillin-resistant Staphylococcus aureus. Food Sci Biotechnol 25: 1671-1675.

Drouin G. 2018. Métabolisme et intérêt nutritionnel de l'acide docosapentaénoïque n-3. Modulation du statut tissulaire en acides gras n-3 par les lipides laitiers alimentaires chez le rat. Rennes 1.

Drouin G, Catheline D, Guillocheau E, et al. 2019a. Comparative effects of dietary n-3 docosapentaenoic acid (DPA), DHA and EPA on plasma lipid parameters, oxidative status and fatty acid tissue composition. J Nutr Biochem 63: 186-196.

Drouin G, Rioux V, Legrand P. 2019b. The n-3 docosapentaenoic acid (DPA): A new player in the n-3 long chain polyunsaturated fatty acid family. Biochimie 159: 36-48.

Fremann D, Linseisen J, Wolfram G. 2002. Dietary conjugated linoleic acid (CLA) intake assessment and possible biomarkers of CLA intake in young women. Public Health Nutr 5: 73-80.

Fuchs CT, Spiteller G. 1999. 9-(3, 4-Dimethyl-5-pentyl-furan-2-yl) nonanoic Acid and 9-(3, 4-DimethyI-5-propyl-furan-2-yl) nonanoic Acid: New Naturally Occurring Peroxidase Inhibitors. Z Naturforsch 54: 932-936.

Ghasemi Fard S, Cameron-Smith D, Sinclair AJ. 2021. n-3 Docosapentaenoic acid: the iceberg n-3 fatty acid. Curr Opin Clin Nutr Metab Care 24: 134-138.

Glass RL, Krick TP, Echardt AE. 1974. New series of fatty acids in northern pike (Esox lucius). Lipids 9: 1004-1008.

Gowda SGB, Fuda H, Tsukui T, Chiba H, Hui, SP. 2020a. Discovery of eicosapentaenoic acid esters of hydroxy fatty acids as potent Nrf2 activators. Antioxidants 9.

Gowda SGB, Liang C, Gowda D, et al. 2020b. Identification of short chain fatty acid esters of hydroxy fatty acids (SFAHFAs) in murine model by nontargeted analysis using ultra-high-performance liquid chromatography/linear trap quadrupole-Orbitrap mass spectrometry. Rapid Commun Mass Spectrom.

Gowda SGB, Gowda D, Liang C, et al. 2020c. Chemical Labeling Assisted Detection and Identification of Short Chain Fatty Acid Esters of Hydroxy Fatty Acid in Rat Colon and Cecum Contents. Metabolites 10.

Graff G, Gellerman JL, Sand DM, Schlenk H. 1984. Inhibition of blood platelet aggregation by dioxo-ene compounds. Biochim Biophys Acta 799: 143-150.

Guillocheau E, Legrand P, Riou V. 2019. Benefits of natural dietary trans fatty acids towards inflammation, obesity and type 2 diabetes: defining the n-7 trans fatty acid family. OCL 26: 9 .

Guo XF, Tong WF, Ruan Y, Sinclair AJ, Li D. 2020. Different metabolism of EPA, DPA and DHA in humans: A double-blind cross-over study. Prostaglandins Leukot Essent Fatty Acids 158: 102033.
Gurr MI, Harwood JL, Frayn KN. 2002. Lipid Biochemistry. 5th ed. Blackwell Sciences.

Guth H, Grosch W. 1991. Detection of furanoid fatty acids in soyabean oil - cause for the light-induced off-flavour. Eur J Lipid Sci Technol 93: 249-255.

Hammarstedt A, Graham TE, Kahn BB. 2012. Adipose tissue dysregulation and reduced insulin sensitivity in non-obese individuals with enlarged abdominal adipose cells. Diabetol Metab Syndr 4: 42.

Hammarstedt A, Syed I, Vijayakumar A, et al. 2018. Adipose tissue dysfunction is associated with low levels of the novel Palmitic Acid Hydroxystearic Acids. Sci Rep 8: 15757.

Hannemann K, Puchta V, Simon E, Ziegler H, Ziegler G, Spiteller G. 1989. The common occurrence of furan fatty acids in plants. Lipids 24: 296-298.

Kaur G, Guo XF, Sinclair AJ. 2016. Short update on docosapentaenoic acid: a bioactive long-chain n-3 fatty acid. Curr Opin Clin Nutr Metab Care 19: 88-91.

Khan MA, Pace-Asciak C, Al-Hassan JM, et al. 2018. Furanoid F-Acid F6 Uniquely Induces NETosis Compared to C16 and C18 Fatty Acids in Human Neutrophils. Biomolecules 8: 144-161.

Kimura I, Ichimura A, Ohue-Kitano R, Igarashi M. 2020. Free Fatty Acid Receptors in Health and Disease. Physiol Rev 100: 171-210.

Kimura T, Tajima A, Inahashi Y, et al. 2018. Mumiamicin: Structure and bioactivity of a new furan fatty acid from Mumia sp. YSP2-79. J Gen Appl Microbiol 64: 62-67.

Knechtle P, Diefenbacher M, Greve KB, et al. 2014. The natural diyne-furan fatty acid EV-086 is an inhibitor of fungal delta-9 fatty acid desaturation with efficacy in a model of skin dermatophytosis. Antimicrob Agents Chemother 58: 455-466.

Kolar MJ, Konduri S, Chang T, et al. 2019. Linoleic acid esters of hydroxy linoleic acids are anti-inflammatory lipids found in plants and mammals. J Biol Chem 294: 10698-10707.

Kuda O, Brezinova M, Rombaldova M, et al. (2016). Docosahexaenoic Acid-Derived Fatty Acid Esters of Hydroxy Fatty Acids (FAHFAs) With Anti-inflammatory Properties. Diabetes 65: 2580-2590.

Kuda O, Brezinova M, Silhavy J, et al. 2018. Nrf2-mediated antioxidant defense and peroxiredoxin 6 are linked to biosynthesis of palmitic acid ester of 9-hydroxystearic acid. Diabetes 67: $1190-1199$

Lauvai J, Becker AK, Lehnert K, Schumacher M, et al. 2019. The furan fatty acid $9 \mathrm{~m} 5$ acts as a partial ligand to peroxisome proliferator-activated receptor gamma and enhances adipogenesis in 3T3-L1 preadipocytes. Lipids 54: 277-288.

Lee J, Moraes-Vieira PM, Castoldi A, et al. 2016. Branched Fatty Acid Esters of Hydroxy Fatty Acids (FAHFAs) protect against colitis by regulating gut innate and adaptive immune responses. J Biol Chem 291: 22207-22217.

Lehnen TE, da Silva MR, Camacho A, Marcadenti A, Lehnen AM. 2015. A review on effects of conjugated linoleic fatty acid (CLA) upon body composition and energetic metabolism. J Int Soc Sports Nutr 12: 36.

Lengler I, Buhrke T, Scharmach E, Lampen A. 2012. In-vitro toxicological and proteomic analysis of furan fatty acids which are oxidative metabolites of conjugated linoleic acids. Lipids 47: 1085-1097.

Leray C. 2013. Les lipides. Nutrition et santé. Lavoisier.

Liberati-Cizmek AM, Bilus M, Brkic AL, et al. 2019) Analysis of Fatty Acid Esters of Hydroxyl Fatty Acid in Selected Plant Food. Plant Foods Hum Nutr 74: 235-240. 
Masuchi Buscato MH, Muller F, Vetter W, Weiss J, Salminen H. 2020. Furan fatty acids in enriched omega-3 fish oil: Oxidation kinetics with and without added monomethyl furan fatty acid as potential natural antioxidant. Food Chem 327: 127087.

Mohan H, Brandt SL, Kim JH, et al. 2019. 3-carboxy-4-methyl-5propyl-2-furanpropanoic acid (CMPF) prevents high fat diet-induced insulin resistance via maintenance of hepatic lipid homeostasis. Diabetes Obes Metab 21: 61-72.

Moraes-Vieira PM, Saghatelian A, Kahn BB. 2016. GLUT4 Expression in Adipocytes Regulates De Novo Lipogenesis and Levels of a Novel Class of Lipids With Antidiabetic and Antiinflammatory Effects. Diabetes 65: 1808-1815.

Okada Y, Kaneko M, Okajima H. 1996. Hydroxyl radical scavenging activity of naturally occurring furan fatty acids. Biol Pharm Bull 19: $1607-1610$.

Okada Y, Okajima H, Konishi H, 1990. Antioxidant effect of naturally occurring furan fatty acids on oxidation of linoleic acid in aqueous dispersion. JAOCS 67: 858-862.

Oteng AB, Kersten S. 2020. Mechanisms of Action of trans Fatty Acids. Adv Nutr 11: 697-708.

Pakiet A, Wilczynski M, Rostkowska O, et al. 2020. The Effect of One Anastomosis Gastric Bypass on Branched-Chain Fatty Acid and Branched-Chain Amino Acid Metabolism in Subjects with Morbid Obesity. Obes Surg 30: 304-312.

Parodi P.W. 2003. Conjugated linoleic acid in food. In: Sebedio JL, Christie WW, Adlof R, eds. Advances in conjugated linoleic acid research. Champaign: AOCS Press, pp. 101-122.

Pham TH, Vidal NP, Manful CF. 2019. Moose and Caribou as Novel Sources of Functional Lipids: Fatty Acid Esters of Hydroxy Fatty Acids, Diglycerides and Monoacetyldiglycerides. Molecules 24: 232-247.

Prentice KJ, Wendell SG, Liu Y, et al. 2018. CMPF, a Metabolite Formed Upon Prescription Omega-3-Acid Ethyl Ester Supplementation, Prevents and Reverses Steatosis. EBio Med 27: 200-213.

Qiu B, Wang Q, Liu W, et al. 2018. Biological effects of trans fatty acids and their possible roles in the lipid rafts in apoptosis regulation. Cell Biol Int 42: 904-912.

Ran-Ressler R.R, Bae S, Lawrence P, Wang DH, Brenna JT. 2014. Branched-chain fatty acid content of foods and estimated intake in the USA. Br J Nutr 112: 565-572.

Ran-Ressler RR, Sim D, O'Donnell-Megaro AM, Bauman DE, Barbano DM, Brenna JT. 2011. Branched chain fatty acid content of United States retail cow's milk and implications for dietary intake. Lipids 46: 569-576.

Richter CK, Bisselou KS, Nordgren TM. 2019. n-3 Docosapentaenoic Acid Intake and Relationship with Plasma Long-Chain n-3 Fatty Acid Concentrations in the United States: NHANES 2003-2014. Lipids 54: 221-230.

Ritzenthaler KL, McGuire MK, Falen R, Shultz TD, Dasgupta N, McGuire MA. 2001. Estimation of conjugated linoleic acid intake by written dietary assessment methodologies underestimates actual intake evaluated by food duplicate methodology. $J$ Nutr 131: 1548-1554.

Rodriguez JP, Guijas C, Astudillo AM, Rubio JM, Balboa MA, Balsinde J. 2019. Sequestration of 9-Hydroxystearic Acid in FAHFA (Fatty Acid Esters of Hydroxy Fatty Acids) as a Protective Mechanism for Colon Carcinoma Cells to Avoid Apoptotic Cell Death. Cancers 11.

Smith U, Kahn BB. 2016. Adipose tissue regulates insulin sensitivity: role of adipogenesis, de novo lipogenesis and novel lipids. $J$ Intern Med 280: 465-475.
Spiteller G. 2005. The relation of lipid peroxidation processes with atherogenesis: a new theory on atherogenesis. Mol Nutr Food Res 49: 999-1013.

Syed I, Lee J, Moraes-Vieira PM, et al. 2018. Palmitic Acid Hydroxystearic Acids Activate GPR40, Which Is Involved in Their Beneficial Effects on Glucose Homeostasis. Cell Metab 27: 419-427 e414.

Tan D, Ertunc ME, Konduri S, et al. 2019. Discovery of FAHFAContaining Triacylglycerols and Their Metabolic Regulation. $J$ Am Chem Soc 141: 8798-8806.

Taormina VM, Unger AL, Schiksnis MR, Torres-Gonzalez M, Kraft J. 2020. Branched-Chain Fatty Acids-An Underexplored Class of Dairy-Derived Fatty Acids. Nutrients 12: 28756-22872.

Tovar J, de Mello VD, Nilsson A, et al. 2017. Reduction in cardiometabolic risk factors by a multifunctional diet is mediated via several branches of metabolism as evidenced by nontargeted metabolite profiling approach. Mol Nutr Food Res 61.

Vetter W, Laure S, Wendlinger C, Mattes A, Smith AWT, Knight DW. 2012. Determination of Furan Fatty Acids in Food Samples. J Am Oil Chem Soc 89: 1501-1508.

von Schacky C, Harris WS. 2018. Why docosapentaenoic acid is not included in the Omega-3 Index. Prostaglandins Leukot Essent Fatty Acids 135: 18-21.

Wahl HG, Liebich HM, Hoffmann A. 1994. Identification of fatty acid methyl esters as minor components of fish oil by multidimensional GC-MSD: New furan fatty acids. J Separation Sci 17: 308-311.

Wakimoto T, Kondo H, Nii H, et al. 2011. Furan fatty acid as an antiinflammatory component from the green-lipped mussel Perna canaliculus. Proc Natl Acad Sci U S A 108: 17533-17537.

Wallace M, Green CR, Roberts LS, et al. 2018. Enzyme promiscuity drives branched-chain fatty acid synthesis in adipose tissues. Nat Chem Biol 14: 1021-1031.

Wang D. 2017. Branched chain fatty acids (BCFA) in nature: fish, fermented food and sea lion vernix caseosa R. Cornell University, $116 \mathrm{p}$.

Wang DH, Jackson JR, Twining C, et al. 2016. Saturated Branched Chain, Normal Odd-Carbon-Numbered, and n-3 (Omega-3) Polyunsaturated Fatty Acids in Freshwater Fish in the Northeastern United States. J Agric Food Chem 64: 7512-7519.

Wang J, Han L, Wang D, Li P, Shahidi F. 2020a. Conjugated Fatty Acids in Muscle Food Products and Their Potential Health Benefits: A Review. J Agric Food Chem 68: 13530-13540.

Wang Y, Pritchard GJ, Kimber MC. 2020b. A General Convergent Strategy for the Synthesis of Tetra-Substituted Furan Fatty Acids (FuFAs). Eur JOC 2020: 2914-2922.

Wendlinger C, Vetter W. 2014. High concentrations of furan fatty acids in organic butter samples from the German market. J Agric Food Chem 62: 8740-8744.

Wu X, Hammond EG, White PJ, Fehr W. 1997. Analysis of furanoid esters in soybean oil and the effect of variety and environment on furanoid ester content. JAOCS 74: 1099-1103.

Yore MM, Syed I, Moraes-Vieira PM, et al. 2014. Discovery of a class of endogenous mammalian lipids with anti-diabetic and antiinflammatory effects. Cell 159: 318-332.

Yurawecz MP, Hood JK, Mossoba MM, Roach JA, Ku Y. 1995. Furan fatty acids determined as oxidation products of conjugated octadecadienoic acid. Lipids 30: 595-598.

Zheng JS, Lin M, Imamura F, et al. 2016. Serum metabolomics profiles in response to $\mathrm{n}-3$ fatty acids in Chinese patients with type 2 diabetes: a double-blind randomised controlled trial. Sci Rep 6: 29522. 
Zhu QF, Yan JW, Gao Y, Zhang JW, Yuan BF, Feng YQ. 2017. Highly sensitive determination of fatty acid esters of hydroxyl fatty acids by liquid chromatography-mass spectrometry. J Chromatogr B Analyt Technol Biomed Life Sci 1061-1062: 34-40.
Zhu QF, Yan JW, Zhang TY, Xiao HM, Feng YQ. 2018. Comprehensive Screening and Identification of Fatty Acid Esters of Hydroxy Fatty Acids in Plant Tissues by Chemical Isotope Labeling-Assisted Liquid Chromatography-Mass Spectrometry. Anal Chem 90: 10056-10063.

Cite this article as: Coudray C, Durand E, Balas L, Sultan A, Casas F, Feillet-Coudray C. 2021. Potential favourable health effects of some dietary uncommon fatty acids. OCL 28: 41. 